\title{
UMA ANÁLISE SOBRE A SUPERVISÃO E A AVALIAÇÃO DOS ESTÁGIOS CURRICULARES EM UMA LICENCIATURA À DISTÂNCIA
}

\author{
AN ANALYSIS ON SUPERVISION AND AN EVALUATION OF CURRICULAR STAGES ON A \\ DISTANCE DEGREE
}

\section{LOS DESAFÍOS DE LA SUPERVISIÓN Y DE LA EVALUACIÓN DE PRÁCTICAS CURRICULARES EN UNA LICENCIATURA A DISTANCIA}

\author{
Layla Júlia Gomes Mattos ${ }^{1}$ \\ Silvana Claudia dos Santos ${ }^{2}$
}

\begin{abstract}
RESUMO
Este artigo tem como objetivo apresentar resultados de uma pesquisa que teve como foco o modo como 0 estágio supervisionado se desenvolveu em um curso de licenciatura em matemática a distância de uma universidade federal mineira. A perspectiva teórica que fundamentou esta investigação compreende o estágio como um dos elementos articuladores dos conhecimentos específicos da profissão e o campo de atuação profissional, no qual teoria e prática não são vistas como momentos distintos da formação. Trata-se de uma pesquisa qualitativa, cujos dados foram coletados por meio de análise documental e entrevistas semiestruturadas realizadas junto à docente supervisora do estágio, bem como com alunas do curso. Com base na análise dos dados, foi possível inferir que a supervisão dos estágios consiste em um momento de pouca intervenção docente e muita expectativa sobre o estagiário, configurando uma parceria de pouco diálogo. Faz-se urgente uma proposta de estágio na qual a orientação seja mais ativa e participativa. $\mathrm{Na}$ EaD, cujos pares estão literalmente distantes, os recursos do Ambiente Virtual de Aprendizagem (AVA) precisam ser explorados considerando suas potencialidades. A tríade observação-participação-regência, organizada de maneira mais cíclica, oportunizaria ao aluno reviver as etapas e avaliar possíveis erros e acertos. $O$ relatório é um instrumento de atribuição de notas e confirmação de presença nos estágios. Contudo, acreditamos que as informações contidas nele poderiam ser distribuídas em momentos específicos, explorando ferramentas do AVA, reutilizando as informações de forma mais objetiva e direcionada às discussões relacionadas ao momento do estágio em que os alunos estiverem experimentando.
\end{abstract}

PALAVRAS-CHAVE: Educação a Distância; Formação Inicial de Professores; Educação Matemática; Tecnologias na Educação.

\begin{abstract}
This article aims to show the results of research that focused on how the supervised internship was developed in a licensure degree in mathematics based on distance education from a Federal University of Minas Gerais. The theoretical perspective that underlies this research comprises the internship as one of the articulating elements of the specific knowledge of the profession and the professional area activity, in which theory and practice are not seen as distinct moments of formation. This is qualitative research, and data were collected through documentary analysis and semi-structured interviews with the internship supervisor, as well as students of the course. Based on data analysis was possible to infer that the supervisor internship consists of a moment with a little teacher intervention and much expectation about the student, setting up a partnership with little dialogue. There is an urgent need for a new internship proposal in which orientation is more active and participatory. In the Distance Education (DE) whose peers are distant, the resources of the Virtual Learning Environment (VLE) need to be explored considering their potentialities. The observationparticipation-regency triad, organized more cyclically would allow the student to relive the steps and evaluate
\end{abstract}

\footnotetext{
1 Pedagoga e Mestre em Educação pela Universidade Federal de Viçosa - MG, campus Viçosa. Professora do Ensino Básico, Técnico e Tecnológico do Instituto Federal de Minas Gerais - IFMG, campus Ouro Preto, vinculada à Coordenação de Educação - CODAEDU. E-mail: laylajgmattos@gmail.com

2 Mestre em Educação Matemática Doutora em Educação Matemática Programa de Pós-Graduação em Educação Matemática, Unesp, Rio Claro. Docente do Departamento de Educação e do Programa de Pós-graduação em Educação da UFV. Coordenadora do Grupo de Atenção às Tecnologias na Educação. E-mail: silvana.santos@ufv.br
} 
possible mistakes and correctness. The report is an instrument for assigning notes and confirming attendance at the stages. However, we believe that the information contained in it could be distributed at specific times, exploring VLE tools, using information more objectively and directed to discussions related to the internship moments that students are experiencing.

KEYWORDS: Distance Education; Initial Teacher Training; Mathematical Education; Technologies in Education.

\section{RESUMEN}

El objetivo de este artículo es presentar los resultados de una pesquisa que tuvo como enfoque el modo como la práctica docente supervisada se desarrolló en un curso de licenciatura en matemática a distancia de una Universidad Federal de Minas Gerais. La perspectiva teórica en que se ha basado esta investigación comprende la práctica docente como uno de los elementos articuladores de los conocimientos específicos de la profesión y del campo de actuación profesional, en que teoría y práctica no son entendidas como momentos distintos de la formación. Se trata de una pesquisa cualitativa, en que los datos fueron recolectados a través de análisis documental y entrevistas semiestructuradas realizadas junto a la docente supervisora de las prácticas, así como con alumnas del curso. Basado en el análisis de los datos, fue posible inferir que la supervisión de las prácticas consiste en un momento de poca intervención docente y de bastante expectativas sobre el practicante, configurando una cooperación de poco dialogo. Se hace urgente una propuesta de práctica en que la orientación sea más activa y participativa. En la EaD, en que los pares están literalmente distantes, los recursos del Ambiente Virtual de Aprendizaje (AVA) necesitan ser explorados considerando sus potencialidades. La triad observación-participación-regencia, organizada de manera más cíclica, daría oportunidad al alumno a revivir etapas y evaluar posibles errores y aciertos. El informe es un instrumento de evaluación y de confirmación de presencia en las prácticas. Sin embargo, creemos que las informaciones contenidas en él podrían ser distribuidas en momentos específicos, explorando las herramientas del AVA, reutilizando las informaciones de manera más objetiva y orientada hacia las discusiones relacionadas al momento de la práctica en que los alumnos estuvieren experimentando.

PALABRAS CLAVES: Educación a Distancia; Formación inicial de Maestros; Educación Matemática; Tecnologías en la Educación.

\section{CONSIDERAÇÕES INICIAIS}

Os estágios são considerados elementos fundamentais para formação de professores, a expectativa é que neles os alunos encontrem o elo entre a teoria e a prática. No entanto, essa perspectiva tem sido contestada, evidenciando a necessidade de um diálogo efetivo entre tais elementos da formação acadêmica durante todo o curso, contrariando a lógica tecnicista na qual os cursos de graduação são organizados. Ainda hoje persiste a lógica "três mais um" nos cursos de formação, embora todas as críticas delegadas a esse modelo, na qual os alunos têm três anos dedicados a estudos em disciplinas tidas por teóricas e, por fim, no último ano de curso, vivenciam as experiências práticas por meio de estágios supervisionados (DINIZ-PEREIRA, 1999).

Contrárias a essa proposta, acreditamos que o estágio supervisionado deveria ser elemento articulador dos conhecimentos específicos da profissão e, não mais, o momento de transição entre o conteúdo acadêmico e a experiência do campo de atuação profissional, mantendo diálogo ativo com as demais disciplinas do curso. 
Pensamos em um estágio que seja elaborado e experimentado de forma alternada, cíclica, cuja presença do aluno no futuro campo de atuação profissional não se restrinja às suas interpretações, mas tenha a presença participativa do professor que o orienta, promovendo idas e vindas acompanhadas de partilha, reflexão e orientação para a turma toda. Tal proposta oportunizaria uma experiência mais significativa para "observação - participação - regência, tripé que tem sido a base da organização dos estágios. Assim, as experiências poderiam ser ouvidas e problematizadas, e não apenas relatadas ao final do semestre em forma de relatórios, sobre os quais, muitas vezes, o aluno não receberá retorno.

Nessa perspectiva, optamos por investigar como se dá o processo de supervisão dos estágios, buscando compreender quais caminhos são percorridos por um professor que orienta alunos em uma licenciatura em matemática de uma universidade pública mineira. A opção por esse contexto se justifica por se tratar de uma modalidade que tem se tornado presente na formação de professores e ainda não tem modelos definidos. A Educação a Distância (EaD) tem como base inspiradora uma cultura presencialista já consolidada, e a partir dela faz adaptações via ambientes virtuais de aprendizagem (AVA) mediados por tecnologias digitais (QUARANTA, 2011; FELDKERCHER, 2011; LIMA, 2013; ROCHA, 2013; SANTOS, 2014, ÁLVARES, 2015; MATTOS, 2017). As propostas de formação desenvolvidas no Brasil não contemplam as especificidades que a modalidade evidencia, ou, por outra perspectiva, apontam para a necessidade de reconhecermos tais especificidades, como público-alvo, recursos utilizáveis, formação profissional capacitada para uso das mídias digitais, formato e qualidade de material didático, definição de profissionais essenciais para o desenvolvimento dos processos de ensino e de aprendizagem, entre outros. Diante disso, buscamos compreender como acontece o trabalho de supervisão dos estágios da grade curricular de um curso de licenciatura ofertada a distância por uma universidade federal mineira vinculada à Universidade Aberta do Brasil (UAB) 3 .

\section{PERCURSO METODOLÓGICO}

\footnotetext{
3 O programa busca ampliar e interiorizar a oferta de cursos e programas de educação superior, por meio da educação a distância. A prioridade é oferecer formação inicial a professores em efetivo exercício na educação básica pública, porém ainda sem graduação, além de formação continuada àqueles já graduados. Também pretende ofertar cursos a dirigentes, gestores e outros profissionais da educação básica da rede pública. Outro objetivo do programa é reduzir as desigualdades na oferta de ensino superior e desenvolver um amplo sistema nacional de educação superior a distância. Há polos de apoio para o desenvolvimento de atividades pedagógicas presenciais, em que os alunos entram em contato com tutores e professores e têm acesso a biblioteca e laboratórios de informática, biologia, química e física. Uma das propostas da Universidade Aberta do Brasil (UAB) é formar professores e outros profissionais de educação nas áreas da diversidade. $O$ objetivo é a disseminação e o desenvolvimento de metodologias educacionais de inserção dos temas de áreas como educação de jovens e adultos, educação ambiental, educação patrimonial, educação para os direitos humanos, educação das relações étnico-raciais, de gênero e orientação sexual e temas da atualidade no cotidiano das práticas das redes de ensino pública e privada de educação básica no Brasil. Fonte: http://portal.mec.gov.br/politica-deeducacao-inclusiva?id=12265.
} 
A título de contextualização, o curso analisado iniciou em 2011 para atender às demandas de formação do Plano Nacional de Formação de Professores (Parfor) ${ }^{4}$ e, posteriormente, preencheu as vagas ociosas por demanda social. A partir dos dados produzidos nesse contexto, acreditamos que podemos contribuir com as discussões acerca de como têm sido organizados os estágios na modalidade a distância e, de modo mais amplo, fomentar o debate acerca das possibilidades e desafios da EaD no país.

Cabe destacar que a pesquisa que deu origem a esse artigo (MATTOS, 2017) foi desenvolvida no âmbito do Grupo de pesquisa GATE, sediado no Departamento de Educação da Universidade Federal de Viçosa, e está relacionada a outras pesquisas que também envolveram a temática da EaD em diferentes aspectos. Desse modo, buscamos contribuir com a produção de um mosaico de pesquisas (BORBA, 2004; MALHEIROS; BORBA; DINIZ, 2005; SANTOS; VIEL, 2013). Santos e Viel (2013) explicam que a metáfora do mosaico serve para ilustrar pesquisas que tomam o mesmo objeto de estudo ou o mesmo contexto, porém com focos ou perspectivas teóricas distintas. No caso de nosso Grupo de Pesquisa, foram desenvolvidas investigações sobre evasão (MIRANDA, 2016), as necessidades formativas de tutores (FIGUEIRA, 2015), o planejamento do ensino e a produção de materiais didáticos (CASTRO, 2016) e sobre o papel das tecnologias digitais (CAMPOS, 2018). Com exceção desta última, que analisou vários cursos de licenciatura em matemática a distância, todas as demais tiveram o mesmo curso de licenciatura como contexto de pesquisa. Desse modo, foi possível notar que cada investigação, ou cada membro do Grupo de pesquisa, são peças chave que compõem a construção do mosaico e colaboram na compreensão de um determinado fenômeno, de modo que esse processo pode ser flexível, pois suas peças podem em alguns momentos abrir espaços ou se sobreporem parcialmente a outras.

Nossos estudos têm se embasado em uma abordagem qualitativa de pesquisa, visto que 0 "as questões desenvolvidas para orientar um estudo qualitativo devem ser de natureza mais aberta e devem revelar maior preocupação pelo processo e significado, e não pelas suas causas e efeitos" (BOGDAN; BIKLEN, 1999, p. 209). A escolha por essa perspectiva de análise também se justifica porque trabalhar sob essa ótica é "[...] apreender o caráter complexo e multidimensional dos fenômenos em sua manifestação natural" (ANDRÉ, 1983, p. 66).

\footnotetext{
${ }^{4} \mathrm{O}$ primeiro Plano Nacional de Formação dos Professores da Educação Básica tinha a intenção de formar, em cinco anos, 330 mil professores que atuassem na educação básica e ainda não fossem graduados. Ainda segundo o MEC, de acordo com Educacenso 2007, aproximadamente 600 mil professores que atuavam na educação básica pública não possuíam título de graduação ou atuavam em áreas diferentes da qual eram formados. Fonte: http://portal.mec.gov.br/plano-nacional-de-formacao-de-professores
} 
$\mathrm{Na}$ pesquisa que originou este artigo, inicialmente, analisamos documentos oficiais da instituição que regimentavam o estágio supervisionado, visando encontrar aspectos que norteariam o trabalho do docente responsável pela disciplina. Então, analisamos sessenta e seis relatórios de estágio elaborados por alunos do curso, em busca de identificar como os alunos eram orientados e como se relacionavam com as diretrizes propostas a eles. Adiante, com base nas questões levantadas nesses documentos - regimento, projeto pedagógico e relatórios - entrevistamos a professora responsável pela supervisão do estágio na licenciatura estudada; por fim, fundamentados em sua fala e nos demais dados documentais, entrevistamos duas alunas do referido curso. Enfatizamos que os nomes das entrevistadas, seja da docente ou das licenciandas, não serão trazidos no texto com o intuito de preservar as suas identidades. Para tanto, usaremos a denominação "Aluna" acompanhado de um número e quanto à docente supervisora do estágio, apenas buscaremos deixar claro quando os dados se referirem às suas falas. As falas correspondentes as alunas 1 e 2 são dados das entrevistas e/ou relatórios, as demais falas de outros alunos são recortes dos relatórios analisados.

As entrevistas foram organizadas de forma semiestruturada, e para torná-las viáveis, optamos por fazê-las online mediadas pelo chat de uma rede social. Isso se justifica em virtude da distância entre nós e as entrevistadas que se encontravam em cidades diversas. Outro fator que contribuiu para escolha do chat foi a vantagem de que as entrevistas já estariam originalmente transcritas (BORBA; MALHEIROS; ZULATTO, 2007).

A partir daí, nos dedicamos à descrição dos dados, pois, na perspectiva de Goldenberg (1999) os dados qualitativos baseiam-se em descrições detalhadas de situações, visando compreender os sujeitos envolvidos na pesquisa por meio de seus próprios termos. Tal proposta exige do pesquisador uma postura flexível e criativa no momento de coleta e de análise. Além disso, para Zanten (2004), selecionar o que será explorado no material produzido por meio da pesquisa é uma tarefa difícil.

É como se fosse um filme no qual não se pode mostrar tudo, porque nunca se mostra tudo 0 que se filmou, mas há de se mostrar aquilo que é realmente representativo, importante. Para isso há um trabalho de montagem, complexo, que tampouco está nos manuais de investigação (ZANTEN, 2004, p. 34-35).

Assumimos esse olhar sobre os dados visando criar categorias de análise, investindo, também, em um diálogo constante com o referencial teórico em busca de encontrar características próprias da supervisão do estágio no contexto da EaD.

\section{AS LICENCIATURAS A DISTÂNCIA E A OFERTA DOS ESTÁGIOS}


A EaD se tornou uma sigla conhecida e isso se deve à expansão das licenciaturas na última década, diante das demandas nacionais de formação professores. A Lei de Diretrizes e Bases da Educação (LDB), ao exigir que a formação dos professores seja de nível superior, colabora com 0 crescimento de matrículas nesses cursos, atendendo, principalmente, professores da rede pública de ensino que não cumpriam essa exigência. No período entre 2001 e 2011 é possível observar um crescimento de $46 \%$ no número de matrículas nos cursos de nível superior. Em 2001, 53,8\% das matrículas foram feitas na rede privada e os outros $46,2 \%$ na rede pública, e em sua maioria no ensino presencial, contando com apenas $0,6 \%$ das matrículas na modalidade à distância. Em dez anos, no entanto, esse número cresceu para 31,06 \%. (BARRETTO, 2015).

Porém, diante de todo crescimento, Barreto (2015) evidencia algumas dificuldades no modelo ofertado pelas instituições de nível superior, tais como: pouca discussão do projeto pedagógico elaborado para os cursos, promovendo uma reprodução do que é vivido na modalidade presencial; fragmentação do trabalho que cabe ao professor, sobrecarregando tutores; precarização da contratação de tutores e atuação de tutores; criação de estruturas paralelas que não promovem a integração entre os cursos; valoração diferenciada entre professores que se dedicam a pesquisa e os que se dedicam a formação docente, sendo os últimos os menos bem avaliados.

Outro dado importante é que evasão nos cursos na EaD é aproximadamente de $80 \%$, de acordo estudos isso se justifica por causa das dificuldades enfrentadas pelos alunos de administrarem a rotina de estudos e de recursos necessários para permanecer na modalidade, entre outros motivos (GATTI, 2013-2014).

Observamos que a EaD está se tornando cada vez mais comum, no sentido de que tem alcançado muitos alunos, como os dados de Barretto (2015) evidenciam. Entretanto, conjuntamente a isso, muitas questões sobre seus efeitos na educação brasileira, sobre qualidade dos cursos ofertados, sobre o interesse das instituições privadas em promovê-la, entre outros diversos aspectos, têm sido alvo de indagações e reflexões dentro e fora da comunidade acadêmica. Pesquisadores citados anteriormente, que se debruçaram sobre o estágio na modalidade, concordam que há uma defasagem na organização da modalidade, negligenciando, principalmente, a distribuição de papéis, a utilização de recurso e o reconhecimento de atributos específicos da EaD. A reprodução do modelo presencial é um dos pontos mais acentuados e aponta para uma indispensável elaboração de fundamentos característicos para a modalidade. Visto que essa "customização" do ensino presencial, vem gerando a formação precária (QUARANTA, 2011; FELDKERCHER, 2011; LIMA, 2013; ROCHA, 2013; SANTOS, 2014, ÁLVARES, 2015; MATTOS, 2017). 
Para Reis (2015), a modalidade a distância contempla três elementos essenciais que aparecem em todos os trabalhos citados até o momento: professor, tutor e AVA. Assim, compreendemos que há necessidade de reelaboração de papéis e de condições de trabalho, onde, por exemplo: o professor e tutor tenham formação específica para atuação na modalidade, divisões claras de função e reconhecimento do profissional; o AVA seja recolocado no currículo como elemento fundamental de mediação do processo, sendo elaborado e tendo seus recursos devidamente explorados.

\section{O PAPEL DE SUPERVISOR DAS AÇÕES DOS ESTAGIÁRIOS}

Segundo o regimento da instituição pela qual o curso estudado é ofertado, o estágio compõe um grupo de disciplinas específico, denominado disciplinas de orientação acadêmica, junto, estão as disciplinas direcionadas à monografia, projetos, trabalhos de conclusão de curso (TCC) e atividades complementares. Embora tenham sido colocadas no mesmo grupo de disciplinas, compreendemos que elas demandam caminhos e estratégias distintas de orientação, visto que os processos e os resultados que, por meio delas, são produzidos de modos geralmente diferentes. Ainda assim, não há caracterização dessas disciplinas no documento em estudo, tampouco do papel do orientador de cada uma delas, o que nos impede de compreender claramente o que se espera desse processo de orientação, olhando para os objetivos propostos para essa pesquisa.

Já no projeto pedagógico do curso (UFV, 2014), há dezesseis tópicos referentes às atribuições do professor responsável pelas disciplinas de estágio em cursos de licenciaturas. Essas atribuições são divididas entre atividades de ordem administrativa e pedagógica. Em síntese, além de garantir que o termo de compromisso seja respeitado e que todas as partes tenham ciência do que Ihes compete, é, também, de sua responsabilidade orientar, acompanhar, supervisionar e avaliar os alunos estabelecendo parceria com o professor ou supervisor de estágio nos espaços formais do campo. Além disso, selecionar, contatar e visitar os locais de estágio antes e durante 0 estágio. Como estas, diversas atribuições do orientador da disciplina envolvem contato direto com a escola concedente. No entanto, observamos que o presente documento não garante condições, em se tratando de um curso a distância, para que o professor orientador desempenhe essas funções, tais como transporte e estadia, por exemplo.

Em entrevista, identificamos que a professora responsável pela disciplina de estágio, na respectiva licenciatura, é uma tutora remanejada para função docente, visto que nenhum professor da instituição assumiu as três disciplinas de estágio obrigatórias ao curso. Ela evidencia a 
expectativa de ir às escolas e encontrar com os professores regentes que recebiam os alunos, sendo essa, uma das funções definidas pela instituição como parte do seu trabalho, mas a própria não oferecia condições para tal. Podemos considerar esse ponto como uma especificidade do estágio supervisionado a distância que dificulta o trabalho de orientação e supervisão que a própria instituição propõe. Sabemos que essa realidade não é diferente no ensino presencial, mas, acreditamos que se torna inviável, no caso da EaD, que o professor utilize recursos próprios para realizar essa tarefa que the cabe. Na verdade, pensamos que em nenhuma modalidade isso seja coerente.

A professora afirmou que se inspirou na observação da sua rotina em um cargo de supervisão pedagógica na rede pública de ensino e de materiais cedidos por uma docente do mesmo curso - Licenciatura em Matemática - ofertado no contexto presencial, para desenvolver as funções de orientação que lhe foram designadas.

Consta no regimento que todas as disciplinas oferecidas pelos cursos da Universidade, lócus deste estudo, devem contar com um professor coordenador responsável por sua organização, cujo dever é, por meio eletrônico, apresentar aos alunos matriculados o plano de ensino contendo instruções, metodologias de ensino, critérios de avaliação, conteúdo e bibliografia a ser utilizada (UFV, 2015). No caso das disciplinas de estágio do curso em questão, a respectiva tutora, nos relatou que foi responsável por esse processo de organização, dividindo as disciplinas em: parte teórica, feita a distância com textos e vídeos que, segundo a docente, buscou relacionar com a prática; e parte prática, relacionado à observação, participação e regência vivenciadas pelos estagiários no contexto escolar. O material de orientação foi disponibilizado no Ambiente Virtual de Aprendizagem da instituição, evidenciando a organização das três disciplinas de estágio e a carga horária determinada destinada a cada momento de inserção do aluno na escola. No mais, segundo ela, "As orientações eram feitas via slides e e-mail". Também, afirmou que: "Sempre deixava um horário via chat para conversarmos, mas pouco utilizável. Respondia os e-mails quase que diariamente".

Para Borba, Malheiros e Zulatto (2007) a comunicação por meio da internet viabiliza a combinação de diferentes possibilidades de interação humana, no que se refere ao uso de softwares e interfaces, como também, à liberdade de tempo e/ou espaço. Afirmam, além disso, que:

A ausência física do professor é compensada por uma comunicação intensa, que limita a possibilidade do aluno se sentir sozinho, isolado. Para tanto, suas dúvidas são esclarecidas em um curto espaço de tempo, e sua participação é constantemente incentivada (BORBA; MALHEIROS; ZULATTO, 2007, p. 26).

No contexto do nosso estudo, uma das alunas entrevistadas afirmou que a professora "[...] é muito boa orientadora, sempre deixou tudo muito bem claro sobre os requisitos e os métodos a 
trabalhos e montar os portfólios e tudo mais. Ela só demorava um pouco para responder, rsrsrs [...]" (Aluna 1). Essa comunicação instável relatada pela aluna pode ter favorecido impasses no processo formativo. Ressaltamos, além do mais, a subutilização do AVA, usado unicamente como meio de compartilhar arquivos entre as partes, optando pelo e-mail como, praticamente, o único recurso mediador do processo. Outras possibilidades como: chat, fórum e web-conferências, por exemplo, não são relatados sendo usadas.

O destaque para o uso pouco exploratório das mídias digitais no contexto do curso também aparece nas pesquisas de Quaranta (2011) e Reis (2015) a respeito do estágio na EaD, citadas anteriormente. Quaranta (2011) destaca, além disso, que, como em nosso contexto, o tutor é o responsável por todo processo de orientação dos estagiários, afirmando que não houve um supervisor que acompanhasse esse processo.

Segundo a professora, o primeiro estágio, destinado ao ensino fundamental, contou com a participação ativa dela: "Dei praticamente passo a passo do que eles tinham que fazer". E a fala da Aluna 5, em entrevista, esse passo a passo também aparece:

Ela passou passo a passo como deveríamos agir, nos cedeu documentos necessários para o convênio com a escola e também um plano de estágio para ser desenvolvido com o professor em sala de aula. A cada mês a gente apresentava a atividade que ela estabelecia e no final do semestre entregávamos o relatório (pasta de estágio) do semestre na ordem cronometrada pela professora.

Em complemento a esses relatos de direcionamento direto do trabalho dos estagiários, que ela chama de passo a passo, a Aluna 13 também afirma, no relatório de estágio, que teve acesso a um plano de aula disponibilizado no AVA, e que, sob os moldes dele, elaborou os planos de aula que deveria apresentar à professora e desenvolver na escola. Diante dessas falas, vemos a perspectiva "objetiva" dos alunos e da professora em ter um método definido para que a aula seja desenvolvida da maneira "certa".

Embora acreditemos que as metodologias são importantes para o desempenho do trabalho docente, percebemos que o "como fazer" ou o "como aplicar" ficam restritos a um "acerto" vazio de sentido, dando a entender que oferecer o roteiro para que o aluno siga à risca é formativo, sendo que, na verdade, este seria um bom momento para discutir as diversas possibilidades de roteiros, planos ou técnicas.

Sem a visão pedagógica de que, na metodologia, estão presentes os conceitos, o entendimento de mundo, os valores e a ética profissional do professor, o formador se transforma em um técnico, repassador de fórmulas para ensinar. Assim, este profissional precisa assumir a superação do como fazer, para a compreensão do todo fazer pedagógico, ou seja, de uma posição metodológica que considera a vida dos professores, suas reais necessidades, suas esperanças, seu trabalho, dificuldades e ousadias (LIMA; GONÇALVES, 2009, p. 2007). 
Identificamos que, para os estagiários, o planejamento de uma aula tem significado de modelo de como dar uma boa aula, ou ainda, de obrigação a ser cumprida. Contudo, se houvesse uma reflexão sobre o fazer pedagógico, poderíamos explorar o estágio para, em algum momento, discutir e elaborar planos de aula, refletindo sobre concepções e práticas pedagógicas que os envolvem, para além de ferramentas e técnicas, voltando o olhar para o contexto do professor, suas habilidades, suas expectativas, suas limitações, entre outros.

\section{A ORIENTAÇÃO DA TRÍADE OBSERVAÇÃO - PARTICIPAÇÃO - REGÊNCIA}

No material elaborado para a orientação dos alunos, cedidos pela professora entrevistada, definiu-se: $30 \mathrm{~h}$ de observação, 30h de participação e 30h de regência para o primeiro estágio; posteriormente, define-se $20 \mathrm{~h}$ para cada uma dessas etapas no segundo estágio; e no último estágio, tem-se 40h para observação, 40h para participação e, por fim, 50h dedicadas à regência. Para as etapas das regências, as ações desempenhadas são definidas pela docente no mesmo material, visando à organização da disciplina e da atuação do aluno, ao qual estamos nos referindo.

A professora afirma que, nesse processo, os alunos apresentaram dificuldade de relacionar teoria e prática, e que como estratégia para promover relações entre os conteúdos aprendidos nas diversas disciplinas do curso e o estágio ela afirma que:

Até tentei, fazer essa integração pedindo que eles buscassem nas disciplinas realizadas atividades para desenvolver no estágio. Pedi na secretaria para me matricular nas disciplinas e ter acesso ao material postado no [...] [AVA]. Sentia falta de encontros com os professores da própria [...] [instituição]. Se o curso é de Licenciatura, há de ter uma maior integração das disciplinas com o ato de ensinar.

Ela também relata que a atuação dos alunos se deu, em sua maior parte, por meio de "observação participante", definida pela mesma como sendo situações nas quais os alunos ajudavam os professores, apesar ter sido deliberada uma carga-horária extensa destinada à regência. Aparentemente, as partes envolvidas entendem como regência a aula dada em si, mas, é preciso compreender que 0 trabalho do professor consiste em diversas tarefas para além de preparar e pôr em prática um plano de aula.

Rela et. al. (2006) descrevem o momento da observação e nos ajudam a pensar um pouco sobre essa separação em três momentos definidos para o estágio: observação, participação e regência. Observar, de acordo com as autoras, prevê um olhar e uma descrição de situações do cotidiano escolar que despertem no estagiário a atenção para alguma relação entre comunidade 
escolar envolvida no processo educativo (professores, alunos, funcionários e entre outros), e conceitos estudados.

Nos relatórios de estágio analisados os registros de observação não revelam essa perspectiva de Rela et. al. (2006). A frase repetida diversas vezes nos relatórios, quando os alunos se referem à observação, é: "Sentei no fundo da sala e iniciei minha observação" (Aluna 12), acompanhada de uma descrição pouco significativa sobre 0 andamento da aula.

Segundo Rela et. al. (2006), as situações observadas nos estágios podem ser mediações pedagógicas, comportamentos e fatos que aconteçam no contexto da escola, por exemplo. Além disso, a observação que as autoras descrevem deve partir de um roteiro no qual as orientações pedagógicas são elaboradas pelos supervisores e esmiuçadas pelo critério do "olhar do aluno". Essa preparação, no entanto, não acontece nos estágios que investigamos.

A definição de "observação participante" que a professora aplica ao que ela encontra nos relatórios é um indicativo de que tríade programada para o estágio não representa para os pares um conjunto estratégico de ações vividas no ambiente escolar que visam o estudo das vivências desse espaço. Ações desempenhadas de forma complementar, porém, não linear, como é apresentado no roteiro da orientadora, já que não é necessário, quiçá nem seja possível, parar de observar enquanto se participa. Na verdade, a observação requer novos objetivos durante o processo.

Para nós, é claro que não faria muito sentido chegar à escola executando projetos como se a demanda de trabalho já estivesse compreendida, pois essa postura reforçaria a ideia de que 0 estágio é um momento de aplicação da teoria, e acreditamos que não o é. Contudo, reservar um tempo definido de 20h, por exemplo, para observar, sem nortear o que se pretende olhar, faz da observação um tempo de infrutífero no fundo da sala, que, muitos alunos acabam não respeitando, seja por iniciativa dos mesmos ou dos regentes, como se constata na fala da docente, citada anteriormente.

Dessa realidade, surge a necessidade de observar ao mesmo tempo em que participa, embaralhando observação e regência no meio do processo. Ainda que nesse momento a carga horária fique, de certo modo, indefinida, essa mistura, a nosso ver, é rica em oportunidades de discussão e reflexão sobre o trabalho docente. No entanto, é pouco explorada nas descrições e não é explorada na orientação, em razão de que toda expectativa está posta sobre vivenciar a regência, uma tendência nas orientações de estágio.

Ao analisarmos a fala dos alunos nos relatórios, observamos que, enquanto imersos na escola, os estagiários corrigem e aplicam provas e trabalhos, tiram dúvidas, participam de eventos organizados pela escola, entre outras coisas. Portanto, podemos inferir que a regência acontece muito além de uma atividade programada pelo estagiário. No que é definido como "participação" já 
Ihe é designado funções do professor regente. Assim, desde o momento em que ele passa a interferir na rotina da turma cumprindo tarefas junto, ou, no lugar do professor, ele já experimenta de alguma forma o papel da regência de uma turma.

Apesar disso, elaborar um plano de aula e executá-lo parece ser a "sina" do estágio, tudo culmina em dar uma aula, e o que antecede isso, é só uma introdução. Nessa perspectiva, a escola revelada no currículo, nos alunos, na comunidade e nos diversos sujeitos que a compõe, acaba se resumindo em dados de um relatório que pouco contribui para avaliação do processo e reflexão teoria-prática, além de atestar que o estágio foi cumprindo, visto que essas informações não são discutidas, analisadas e introduzidas de forma intencional no processo de formação do estagiário.

Além do mais, os estagiários, frequentemente descrevem nos relatórios problemas com indisciplina, relatam interrupções nas aulas por motivos externos ao que acontece dentro da sua sala de aula, tais como brigas de alunos no intervalo, paralisação de professores, reunião com os pais e responsáveis etc. Situações essas, mais comuns na profissão docente do que o futuro professor compreende ou, nem mesmo, percebe como realidade da regência que a docência lhe reserva. Dito isso, ressaltamos que a ideia de destinar uma extensa carga horária para regência parece desconsiderar a diversidade de escolas e traz consigo a imagem arraigada do professor aplicador de uma técnica, visto que a expectativa é que estagiário finalize seu estágio com uma boa dose de aulas dadas, para aprender como se faz. Tal perspectiva não é exclusividade da professora orientadora dos estágios que estudamos, mas fruto da racionalidade técnica que acompanha a formação de professores ao longo de décadas, logo, não temos a intenção de responsabiliza-la por essa escolha.

Infelizmente, não é comum que esse processo seja refletido e questionado nem antes, nem durante, e muito menos, depois que o estágio termina. Sendo assim, nem a técnica ou a metodologia desempenhada pelo aluno, por exemplo, passa por uma avaliação qualitativa. Essa questão é problemática, levando em conta que o "[...] estagiário nem sempre compreende a dinâmica do estágio e de sua presença na escola e esse fato dificulta a superação das dificuldades que por certo surgirão no decorrer do processo de realização do estágio supervisionado" (XAVIER, 2009, p. 2667).

Com esse problema reconhecido, faz-se necessária, então, clareza nas definições, dos objetivos e possibilidades do trabalho do estagiário, para que ele, por sua vez, desenvolva-o buscando compreender as suas ações e não somente execute-as.

No final do material de orientação a professora propõe que os alunos procurem as escolas nas quais pretendem estagiar, preencham o termo de compromisso em três vias e participem do fórum "Tira dúvidas". Esse fórum, não aparece em nenhuma fala, além desse material. Como a 
professora relata que a orientação se deu por meio da apresentação de slides e as dúvidas eram sanadas via correio eletrônico, entendemos que, possivelmente, esse fórum não foi explorado.

Ainda nos referindo à conclusão da orientação via slide, a orientadora informa que a cada etapa será atribuída uma pontuação e que não haverá tutores para essa disciplina, disponibilizando seus contatos. Ao atentarmos para as definições, observamos um interesse em direcionar as etapas de atuação do aluno, e, embora os alunos tenham se dedicado mais a observar e apoiar o professor quando necessário, do que as horas reservadas para regência, a orientadora afirma que [...] tudo é válido, pois muitos alunos foi a primeira vez que entraram em uma sala de aula e escola. Em contrapartida, a Aluna 2, que já é graduada em uma licenciatura - a Pedagogia - sugere que [...] 0 aluno que já possui curso superior e atua na área tenha a carga horária reduzida.

A partir da fala da docente e da Aluna 2, nos colocamos a pensar se todo tipo de experiência no contexto da escola é significativo para o processo de formação? A experiência em si é formadora? $O$ fato de ter contato com a escola já atribui ao evento 0 caráter de formador do profissional, em nosso caso, o docente? Em busca de respostas para perguntas semelhantes a essa, Schwartz (2010, p. 44) afirma que é preciso:

[...] distinguir a experiência do trabalho e o trabalho como experiência. Na experiência, pode haver rotinas e, se não dizemos mais, a experiência pode ser um obstáculo à ampliação ou ao enriquecimento. Com efeito, não é porque ficamos muito tempo em uma mesma situação de trabalho, que capitalizamos fortemente algo e a simples duração não produz como tal algo positivo.

Partimos desse ponto de vista para defender que diversas horas dedicadas a observar, participar e reger podem não estar contribuindo para que o processo de formação seja enriquecido pela inserção no campo de trabalho, visto o desamparo do estagiário ao ter que fazer sozinho as inferências formativas das ações pedagógicas que vivencia no espaço escolar.

Os estágios são definidos no regimento como disciplinas de orientação pedagógica, e entendidos como momentos de pouca intervenção do docente, cabendo a ele supervisionar o processo, uma vez que a supervisão tem se resumido a garantir sua efetivação. Precisaríamos, então, renomear o orientador com o título de professor de estágio? Para, assim, fazer com que 0 trabalho compreenda discutir propostas de intervenção, fomentar debates sobre os relatos vindos das escolas, estudar com os alunos as situações advindas da inserção no campo de trabalho, para além da orientação do "como fazer", ou do "como dar uma aula"? De fato, não é "culpa" dos docentes que se espere pouca intervenção, e não cabe a nós definir que seu papel não tem sido bem desempenhado, mas a crítica que fazemos é ao modelo que vem se consolidando nas instituições de ensino superior. 
Diante disso, pontuamos que há um problema com a concepção de estágio, pois, é dela que parte o que cabe ao professor e ao estagiário, por exemplo. 0 formato do estágio tem 0 docente que faz jus a sua proposta, afinal, esse momento é interpretado como a hora de o estagiário praticar, tudo já foi devidamente teoricamente aprendido. Repensar o papel do orientador, sem repensar o estágio, a formação docente, entre outros elementos, é colocar sobre esse docente toda a responsabilidade de fazer com que o estágio se efetive como espaço de formação.

Ao analisarmos os relatos da professora, suas orientações e os relatórios, percebemos que há um conflito entre como fazer e o que fazer em cada etapa do estágio. Essa separação de carga horária definida para cada momento do estágio, em diversos casos, não é respeitada, e participação, observação e regência se misturam sem demonstrar clareza das definições propostas para cada etapa. Essa dificuldade de discernir o que é preciso saber para ir a campo estagiar e 0 que se quer aprender no campo, aponta para um problema que Schwartz (2010) define como dupla antecipação:

[...] num sentido, o saber formal antecipa a experiência (em qualquer situação de trabalho há, antes que você entre nele, saberes, regras, que permitem antecipar sua maneira de fazer). Mas, reciprocamente, o tratamento de situações de trabalho como encontros de encontros obriga a retrabalhar os conceitos que se dão como missão antecipá-los e assim, de uma maneira diferente dos saberes formais, a experiência antecipa o trabalho por vir dos conceptores. Dupla antecipação então e cada uma tem seu papel (SCHWARTZ, 2010, p. 46).

Pensando no estágio, precisamos defender firmemente que o estagiário vá para a escola com noções de saberes, regras e situações de trabalho que pertencem a esse lugar, por exemplo, elaborados em planos de possíveis intervenções nesse meio, compreendendo, no entanto, que seu planejamento e suas concepções se relacionarão com o contexto no qual será inserido, suas particularidades e suas demandas. Nessa experiência, possivelmente, vivenciará condições de trabalho diferentes das que previamente considerou, como nos casos que estudamos, nos quais alunos tiveram muitos problemas com indisciplinas enquanto outros encontraram alunos participativos e interessados.

Ainda que a orientadora tenha apresentado o que esperava dos alunos em cada etapa, nas autoavaliações de alguns relatórios, os alunos sugerem: que se deve dar mais exemplos de como preencher relatórios; que os critérios de avaliação sejam apresentados na primeira semana; que se dê mais explicações de como deve ser, como fazer, como é o estágio; que se estabeleça modelos de preenchimentos etc. Já os Alunos 3 e 11 afirmam que as definições do roteiro da orientadora foram suficientes e consideraram a programação do estágio bem distribuída, sem a necessidade de sugestões de mudança. 
Os alunos parecem pedir, não só esclarecimentos, mas sim, uma espécie de manual, ou roteiro detalhado do que fazer na escola e com as informações coletadas nela. Porém, não é disso que estamos falando quando defendemos direcionamento e esclarecimento sobre as definições do estágio. Quando ponderamos sobre esclarecer e direcionar, estamos tentando chamar a atenção para o relacionamento entre teoria e prática para que haja mais diálogo, promovido pelo professor orientador, e menos modelos a serem seguidos. Apoiamos, consequentemente, que os possíveis parâmetros de escola sejam analisados, criticados, repensados e ressignificados, também, durante o estágio.

Como exemplo, tomamos o caso da Aluna 1, que em seu primeiro estágio, descreve uma aula de jogos que o professor regente promove e diz que participou ajudando a tirar dúvidas, mas em sua conclusão afirma que "Não imaginava que poderia ajudar". A estagiária constata a grande dificuldade dos alunos com o conteúdo e evidencia que esses são alunos que pararam de estudar e, ao retornarem, não conseguem assimilar com facilidade todo conteúdo, exigindo, dela e do professor regente, um apoio em quase todas as atividades propostas. Contudo, a fala da estagiária referente à dificuldade de perceber-se útil em sala, revela sua insegurança sobre qual era o seu lugar no estágio e o que ele demandaria dela. 0 trabalho da estagiária, talvez, poderia ter sido potencialmente diferente se tivesse consciência do que deveria fazer e intenção clara do que esperava aprender ao se relacionar com os alunos da escola e com professor regente, buscando experiências que contribuíssem significativamente para sua regência no estágio e na vida profissional.

Garcia (1999) traz a intencionalidade como um elemento chave para que a formação aconteça e é dela que sentimos falta quando o estagiário vai para a escola sem saber que seria "capaz de ajudar". Essa perspectiva poderia servir de base para construção de propostas de estágio em que as orientações não se reduzissem à definição de carga horária para observação, participação e regência, e à elaboração de relatórios cansativos e sem um propósito para além de atribuição de uma nota final.

\section{A AVALIAÇÃO E SUA RELAÇÃO DIRETA COM OS RELATÓRIOS}

No contexto da pesquisa que realizamos, durante todo o processo dos dois primeiros estágios, os alunos são obrigados a preencher relatórios e, no terceiro estágio, a elaborar um portfólio. Ao final do estágio os alunos enviaram esse material via correios e eles foram arquivados na Universidade, sendo este o principal item de apreciação do que acontece no estágio pelo professor orientador. Sobre isso, concordamos com Lüdke (2013) que esses relatórios poderiam 
assegurar um melhor aproveitamento do aprendizado se não fossem vistos apenas como instrumento de avaliação. Para ela, tem-se esquecido que a principal contribuição da avaliação é "[...] fornecer elementos para a melhoria do processo de formação, o que aconteceria se o relatório fosse analisado e considerado pelo avaliador antes de se concluir esse processo, a tempo de introduzir nele esses elementos" (LÜDKE, 2013, p. 126). Além disso, para nós, há um "desperdício" de informações que são preenchidas nos relatórios, sobre a escola e seus sujeitos, por exemplo, e que não são posteriormente discutidas com os estagiários. Os relatórios seguem um modelo, aparentemente padronizado, composto por uma capa com identificação do aluno e da disciplina em que está matriculado, nome da professora e, em geral, apresentam uma foto da escola.

Essa recomendação para que sejam feitos registros em fotografia é da professora orientadora, e na entrevista, a docente não esclarece a sua motivação ao pedir as fotos das escolas e as ações desenvolvidas nelas. No entanto, conjecturamos que, para além de ilustrar os dados apresentados nos relatórios, essa orientação seja, também, uma maneira de se ter "provas" de que o aluno desenvolveu o estágio, pois, como já citado, não haveria condições de a orientadora ir até as escolas. Em seguida, os relatórios contam com uma página de atestado de comparecimento e cumprimento de horas, na qual constam os dados do aluno, a carga horária cumprida, o período e a cidade em que se deram as vivências de estágio e, por fim, a assinatura e carimbo do diretor da escola, servindo como mais uma "garantia" de que o aluno esteve presente.

Adiante, o relatório conta com uma página chamada de ficha de estágio, na qual os estagiários preencheram, mais uma vez, seu nome, e o nome da escola, o ano, as "séries" e as turmas específicas de atuação, turno, e professor regente que iriam acompanhar. Preencheram, também, um quadro com data, carga-horária e atividades que desenvolveram, reservando um espaço para assinatura do professor. No fim da página, registraram o total de horas e coletaram a assinatura e carimbo dos diretores. Até esse ponto da elaboração dos relatórios, compreendemos a necessidade dessas informações e registros, supondo que elas têm o propósito de assegurar à orientadora a efetivação do estágio. Além disso, os alunos são orientados pela docente a colocarem fotografias do desenvolvimento do estágio no decorrer do trabalho, e entendemos que isso funciona, tanto como um recurso de o professor garantir que o aluno realmente fez o estágio, quanto, já mencionado, como uma maneira de avaliar se 0 aluno estava realmente executando os passos estipulados pela orientadora.

Em alguns casos, os alunos não justificavam a exposição das imagens, as anexando ao trabalho de forma aleatória, sem explorá-las. Ora as fotografias aparecem no início, caracterizando a escola, ora no final, destacando as atividades feitas. Além disso, não é comum haver referências às fotos durante os textos dos relatórios. Mas, a maioria dispôs as imagens intercalando com os 
relatos das atividades, misturando fotos dos alunos desenvolvendo atividade, fotos da professora e fotos do espaço físico da escola.

Em seguida, os relatórios contam com um roteiro de conhecimento das escolas por meio do qual seriam coletados dados como: endereço; turno de trabalho; número de professores; número de professores de matemática; número de alunos; recursos diversos como internet, projetor, biblioteca, laboratório de informática, colegiado etc; quem acompanhou ao chegar à escola; formação do professor regente; organização da gestão da escola; se a escola conta com Projeto Político Pedagógico (PPP), entre outras informações sobre a organização e as características físicas da escola. Alguns alunos fazem destaques sobre a instituição que o recebe, como por exemplo, se a escola está localizada em meio a comunidades da zona rural ou periférica, e se conta com poucos recursos.

As perguntas que nos fizemos é: para que servem essas informações que ocupam uma boa parte da redação dos relatórios? Entendemos que muitas dessas informações poderiam ser objetos de pesquisa, visando conhecer, por exemplo, o perfil de escolas em que os alunos estagiam e a relação com problemas como indisciplina, violência, condições de trabalho docente, entre outros diversos temas. No entanto, não encontramos propósito em fazer com que o aluno gaste tempo do estágio resumindo PPP, por exemplo. 0 que há de formação significativa nesse processo, se a interpretação dele fica a cargo do aluno e a leitura avaliativa do professor não lhe dará nenhum retorno?

Não sabemos em que momento o relatório se consolidou como o resultado de estágio, em geral, de outra forma, como o produto que comprova por meio de seus dados que houve efetivamente a inserção na escola, ou, qualquer outro campo de trabalho, e, por consequência, formação do estagiário. Mas, entendemos até aqui, que seu aproveitamento como instrumento de avaliação e apoio ao processo de formação, não tem se mostrado produtivo para o diálogo entre os docentes responsáveis pelas disciplinas de estágios e seus alunos.

Pires (2012, p. 10) afirma que existem iniciativas que buscam mudanças nesse diálogo entre orientador e estagiário. Segundo ela, existem ações no sentido de "[...] reestruturações de currículos, criação de novas coordenações, aumento de carga horária de estágio, aumento do campo de discussão teórica sobre a formação de professores", entre outros. Porém, "[...] os professores orientadores ainda estão muito arraigados a uma prática tradicional, apesar de 0 discurso ser, na maioria das vezes, inovador". Suas práticas de orientação são rodeadas por novas teorias e por formas de tratar a questão do estágio. Todavia, seus pensamentos não chegam à escola, e nem atingem os professores regentes, "[...] já que fica cada um no seu mundo". 
Como exemplo dessa dificuldade de aproximação entre a fala do professor orientador e a do regente, vemos as fichas de avaliação qualitativa da regência, que fazem parte do conteúdo dos relatórios os quais analisamos. Nela, além dos dados do aluno e do professor regente - avaliador, consta uma tabela com itens a serem avaliados, tais como: clareza na explicação e domínio do conteúdo; ênfase na aprendizagem significativa; utilização de exemplos cotidianos e contextualização da explicação; adequação à faixa etária; planejamento; entonação da voz, entre outros, totalizando quinze itens a serem contemplados pelo aluno. $A$ avaliação era definida em: $A=$ precisa melhorar nesse item; $B=$ Foi bem, mas pode melhorar nesse item; e $C=$ Foi muito bem, de forma plenamente satisfatória nesse item. Existiram casos em que a ficha foi assinada e carimbada pelo professor avaliador, e em outros, ela veio separada em um envelope anexo ao relatório.

Ao analisar essas fichas, nos questionamos sobre o que acontece com essa avaliação? Há casos em que alunos foram avaliados com A e B e, assim, precisavam melhorar algum aspecto avaliado. Em determinado caso, a regente ainda faz considerações a respeito dos conceitos que atribuiu ao trabalho da estagiária. Contudo, não existiu espaço oportunizado para que a fala da professora regente pudesse fomentar orientação e reflexão sobre as dificuldades apresentadas pela aluna. Em que momento ela poderia aperfeiçoar seu trabalho, discutir sua avaliação e ser orientada sobre suas práticas, se o estágio acabou? Novamente, concordamos que elementos dos relatórios, como esse, realmente precisam ser revistos e inseridos no como caminho de formação, antes dos alunos concluírem os estágios, como lembramos Ludke (2013) anteriormente.

Depois da avaliação, o aluno tem diversas páginas com espaço para seus dados, dados da escola, "série", professor regente, data e horário para preencher, e, logo abaixo disso, cerca de trinta linhas para relatar sua observação, participação e, por fim, regência. Cada dia na escola é preenchido em uma folha diferente. No fim, em geral, os relatórios contam com uma folha solicitando autoavaliação e sugestões de melhoria da disciplina. A maioria dos alunos incluem nessa organização seus planos de aulas, cópias dos exercícios e conteúdos trabalhados no estágio.

Alguns alunos, no espaço de sugestão, pedem que os relatos sejam mais direcionados e esclarecidos, objetivos e sucintos, e até mesmo, que não existam. Segundo uma das alunas, os estágios poderiam ser organizados da mesma forma, porém, sem relatórios, pois, para ela, "o que muda no cotidiano em uma sala de aula é somente o conteúdo e os recursos que o professor utiliza para reger as aulas" (Aluna 10).

Outra estagiária, a Aluna 7, diz que poderiam ser reduzidos os números de relatórios, "pois o cotidiano de uma sala de aula é muito parecido". A fala dos alunos indica que a redação dos relatos é cansativa e toma muito tempo, e não tem apresentado finalidade, já que não há retorno sobre o que escrevem. Seria uma oportunidade de inserir recursos do AVA com fóruns e web 
conferências para promover diálogos a respeito de informações sobre PPP, relação da escola com a comunidade, planejamento, perfil do professor regente que os acompanha, por exemplo, trazendo à tona e discutindo coletivamente as informações que ficariam perdidas nos relatórios?

No aspecto organizacional dos relatórios percebemos que, mesmo estando padronizados para todos os alunos, de modo geral, apresentam pouca e, muitas vezes, repetitiva descrição. Com frequência os alunos relatam como o professor começou a aula, o conteúdo que foi ensinado e comentam o comportamento da turma. Alguns são redigidos à caneta, com baixa legibilidade. Outros, mesmo estando digitados, apresentam uma escrita confusa e desorganizada.

Identificamos, também, a falta de domínio com programas de edição de texto, pois, vários relatórios estão com problemas de formatação e/ou desconfigurados. Essas questões dificultaram a leitura e a sistematização dos dados dessa pesquisa, e acreditamos que, provavelmente, dificultaram a leitura e a avaliação qualitativa desses relatórios por parte da professora orientadora, levando em conta, ainda, o volume expressivo do material. Concluímos que a forma como esses relatórios são organizados não favorecem o exame qualitativo das experiências de estágio, visto que nada se faz com eles após a sua redação, que acrescente espaço de análise, reflexão e formação ao aluno. Os relatórios se tornam um fardo para quem o elabora e para quem o avalia, sem sentido formativo aparente.

No último estágio, o documento é substituído pelo portfólio, que foi elaborado de forma diferente, pois, se tratava de um projeto de intervenção planejado e desenvolvido pelo aluno em parceria com o professor regente e não seguiu o modelo dos relatórios dos dois primeiros estágios.

As únicas coisas que mantiveram o padrão dos primeiros estágios foram as folhas destinadas ao atestado de comparecimento e cumprimento de horas de estágio, e a lista de presença. De modo geral, os portfólios apresentam dados de reconhecimento da escola, muitas vezes repetido de outros relatórios, visto que muitos alunos fizeram os três estágios na mesma escola; caracterização do bairro; caracterização do espaço físico; caracterização da população da escola; PPP, também, por vezes, repetido; reconhecimento da organização escolar (funcionários, alunos, horários, etc.); planejamento da escola; descrição da professora regente, alguns incluem dados pessoais como, número de filho, se é casado (a) e coisas que faz em momentos de lazer; fotos da escola, da turma, do estagiário e do professor regente; e por fim, o projeto, sua execução, e a conclusão do aluno sobre a experiência vivida. Verificamos, também, que, dentre todos os portfólios cedidos pela professora a nós, alguns foram elaborados em grupos.

Questionada sobre sugestões de possíveis mudanças em como esses estágios são organizados, a docente orientadora disse que é preciso: 


\begin{abstract}
Maior investimento no que tange à ida do professor da disciplina de estágio aos polos. Antes de começar o estágio, ir às escolas, conversar com os alunos e professores que receberão esses estagiários; Ter mais integração do estágio com outras disciplinas; $\mathrm{Na}$ grade curricular, não deixar para os últimos períodos. Enviar a todos os polos, livros que foram sugeridos no programa analítico da disciplina. O que adianta ter exemplares na biblioteca se eles não vêm à Viçosa?!!!! (Professora orientadora)
\end{abstract}

Consideramos que ir às escolas e orientar o aluno de perto, como sugere a professora e os documentos da instituição não é uma prática fácil de ser exercida, inclusive no ensino presencial, do qual não temos dados para afirmar que esse acompanhamento acontece. Assim sendo, não podemos afirmar que essa dificuldade se configura em um problema característico da $\mathrm{EaD}$, ainda que elas sejam otimizadas pela diversidade de cidades, pela quantidade de alunos, entre outros pontos que discutimos anteriormente.

Mas, para além de todas as menções que fizemos à necessidade de revisão da proposta de estágio de forma ampla no contexto das licenciaturas, no que diz respeito especificamente à EaD, ressaltamos a carência de comunicação no estágio que investigamos. Esse aspecto precisa ser reelaborado, para tornar as orientações destinadas ao estagiário um caminho efetivamente formativo. Nesse sentido, Borba, Malheiros e Zulato (2007, p. 28), baseados em Alrø e Skovsmove (2006), defendem que

[...] a qualidade da aprendizagem está intimamente ligada à comunicação. As relações entre as pessoas são fatores cruciais na facilitação da aprendizagem, uma vez que aprender é um ato pessoal, mas é moldado em um contexto das relações interpessoais, e o diálogo, como meio de interação, possibilita o enriquecimento mútuo entre as pessoas.

Desse ponto de vista, destacamos que uma marca desse estágio supervisionado à distância se caracteriza na fala da professora e das alunas entrevistadas, que assinalam que a orientação se deu sempre por meio de e-mail e, tendo aberta a possibilidade do chat. Esse aspecto aponta para 0 uso pouco exploratório das tecnologias digitais disponíveis, dito anteriormente, tendo em vista que poderiam ter sido feitas videoaulas, aulas narradas, videoconferências, fóruns, entre outras possibilidades que a modalidade adota e que teriam potencial para promover discussões, reflexões e orientações sobre cada momento dos estágios.

Para Rocha (2013, p. 94), isso acontece porque os professores da EaD vivem o desafio de construir a cultura da modalidade, assim como as competências que cabem aos que a desenvolvem. Segundo ela "[...] a cultura da presencialidade encontra-se entranhada no fazer docente em EaD. As "coisas tecnológicas" trazidas em seu bojo, AVA's, fóruns, chats são elementos que necessitam de tempo, experiência e vontade de mudança [...]". Ainda, em suas palavras, há, também, problemas com a formação dos docentes formadores, pois, de acordo com ela, os 
professores que atuam na EaD têm pouca ou nenhuma formação para atuar em cursos sob seus moldes, "[...]o que empobrece as ações pedagógicas neste âmbito" (ROCHA, 2013, p. 95).

Outro desafio que destacamos é que o número de alunos a ser orientado comumente presente em turmas de cursos ofertados a distância é muito maior do que turmas presenciais, o que pode tornar a orientação desses alunos um grande desafio para um único professor e, obviamente, uma sobrecarga de trabalho. Ao remanejar uma tutora para função de professora, independente da sua formação em Pedagogia e Mestrado em Educação, que por sinal favorecia a sua posição de orientadora, evidencia uma despreocupação da instituição com a disciplina de estágio e como ele seria desenvolvido.

Além disso, o estudo de Miranda (2016) evidencia que houve uma evasão de 90\% de alunos do curso, o que a nosso ver tornou viável a orientação de alunos a distância no formato proposto. Mas, tal questão nos despertou para uma questão: precisamos pensar em uma proposta supervisão de estágio que realmente contemple a EaD, a distância como elemento fundamental das relações professor-alunos e o AVA como instrumento essencial de mediação. Como esperar que 0 professor vá as escolas, assista regências, conheça professores regentes, por exemplo? Os cursos ofertados à distância contam com a evasão para que as disciplinas de estágio "deem certo"?

\section{CONSIDERAÇÕES FINAIS}

Compreendemos que a supervisão das disciplinas de estágio é um espaço de pouca intervenção do docente e muita expectativa sobre o estagiário, o que se configura em uma parceria de pouco diálogo e um processo de formação explorado de forma insuficiente. Ao aluno resta estabelecer as pontes necessárias entre teoria e prática, entre escola e instituição de ensino, entre seus conhecimentos e a experiência vivenciada.

Entendemos que uma nova proposta de estágio na qual a orientação seja mais ativa e participativa se faz urgente. No caso da EaD, cujos alunos e orientadores estão literalmente distantes, os recursos dos AVAs precisam estar disponíveis e serem usados para além do envio de arquivos, e o professor precisa ser figura presente nos "fóruns de dúvidas" como fomentador de debates, criador de questões, e não como um "socorrista" na expectativa de um atendimento de urgência.

A tríade observação-participação-regência dá oportunidades de 0 aluno ter perspectivas diferentes da sala de aula. Contudo, não tem se mostrado efetivas, a partir do fato de que os alunos não conseguem definir seu papel nessas fases com clareza. Assim, pensamos que elas poderiam 
ser organizadas de forma mais cíclica, dando oportunidade de o aluno reviver as etapas e avaliar erros e acertos em busca de aprimoramento e aprendizagem significativa.

Por fim, acreditamos que a avaliação como se dá, via relatórios, não tem retornado ao aluno, alvo dos processos de ensino e de aprendizagem, os resultados que 0 ajudariam a compreender o papel do estágio em sua formação acadêmica. Logo, não tem cumprido papel avaliativo, sendo instrumento de atribuição de notas e confirmação de presença nos estágios. Pensamos que, para que as informações contidas nos relatórios tenham devida importância avaliativa, elas poderiam ser distribuídas em momentos específicos do estágio, explorando outras ferramentas do AVA, reutilizando as informações de forma mais objetiva e direcionada às discussões relacionadas ao momento do estágio em que os alunos estiverem experimentando.

\section{REFERÊNCIAS}

ÁLVARES, Camila Costa de Oliveira Teixeira. A educação superior no Brasil e o Ensino a Distância: uma análise crítica do estágio supervisionado. 2015. 137 pág. Dissertação de Mestrado em Educação, Linguagem e Tecnologias, Universidade Estadual de Goiás - UEG, Anápolis - GO, 2015.

ALVES-MAZZOTTI, Alda Judith. GEWANDSZNAJDER, Fernando. 0 método nas ciências naturais e sociais: pesquisa quantitativa e qualitativa. São Paulo: Pioneira, 1999. 203p.

ANDRÉ, Marli Eliza Dalmazo Afonso de. Texto, contexto e significados: algumas questões na análise de dados qualitativos. Cadernos de Pesquisa. São Paulo, n. 45, p. 66-71, maio 1983.

BOGDAN, Robert C. BIKLEN, Sari kanopp. Uma introdução teoria e aos métodos. Portugal, Porto editora, 1.

BORBA, Marcelo de Carvalho. A pesquisa qualitativa em educação matemática. In: Reunião anual da Anped - Associação Nacional de Pesquisa em Educação, 27, 2004, Caxambu. Anais... Caxambu - MG. 2004.

BORBA, Marcelo de Carvalho; MALHEIROS, Ana Paula dos Santos; ZULATTO, Rúbia Barcelos Amaral. Educação a Distância online. 1. ed. Belo Horizonte: Autêntica, 2007. v. 1. 160p.

BRAGA, Jacqueline. Estágio supervisionado no programa de formação de professores: Tensões e reflexões. Revista Eletrônica de Educação, v. 9, n. 1, p. 251-261, 2015. Disponível em: <http://dx.doi.org/10.14244/198271991073> Acesso em: 2 de abril de 2017.

CAMPOS, June Rodrigues Pereira. Os usos das tecnologias digitais nas licenciaturas em matemática a distância em minas gerais. Dissertação de mestrado. Universidade Federal de UFV, 2018.

CASTRO, Samira Bahia. 0 planejamento do ensino em um curso de licenciatura em matemática a distância: um olhar para a produção do material didático. Relatório Final, referente ao período de março/2015 a fevereiro/2016, apresentado à Universidade Federal de Viçosa, como parte das exigências do PROBIC/FAPEMIG.

DINIZ PEREIRA, Júlio Emílio. As licenciaturas e as novas políticas educacionais para formação docente. Educação \& Sociedade (Impresso), Campinas, v. 68, p. 109-125, 1999. 
FELDKERCHER, Nadiane. 0 estágio na formação de professores presencial e a distância: a experiência do curso de matemática da UFPEL. 2011. (Mestrado acadêmico). UNIVERSIDADE FEDERAL DE PELOTAS, PELOTAS, 2011.

FIGUEIRA, Aline C. Uma análise das necessidades formativas de tutores de um curso de licenciatura em matemática a distância. Relatório Final, referente ao período de outubro/2014 a julho/2015, apresentado à Universidade Federal de Viçosa, como parte das exigências do $\mathrm{PIBIC/CNPq}$.

GARCIA, Carlos Marcelo. Formação de professores: para uma mudança educativa. Porto: Porto Editora Ltda, 1999, capítulo 1, p.17-46.

GOLDENBERG, Mirian. A arte de pesquisar: como fazer pesquisa qualitativa em ciências sociais. Rio de Janeiro: ed. Record, 1999.

LIMA, Marlene Haidem de Souza. O Estágio em um Curso de Pedagogia a Distância: a visão dos alunos. 2013. Dissertação (Mestrado) - Universidade Católica de Santos, Programa de Mestrado em Educação. Santos, 2013.

LÜDKE, Hermengarda Alves Menga. O Lugar do Estágio na Formação de Professores. Educação em Perspectiva, Viçosa, v. 4, n. 1, p. 111-133, jan/jun. 2013.

MALHEIROS, Ana Paula dos Santos; BORBA, Marcelo de Carvalho; DINIZ, Leandro do Nascimento. Doze Anos da Produção Matemática de Estudantes de Biologia em um Ambiente de Modelagem. In: Congresso Nacional de Modelagem e Educação Matemática, 5, 2005. Feira de Santana. Anais... Feira de Santana: Universidade Estadual de Feira de Santana, 2005.

MATTOS, Layla Júlia Gomes Mattos. 0 estágio supervisionado a distância: proposta, organização e prática no contexto da licenciatura em matemática a distância. Dissertação de mestrado, Universidade Federal de Viçosa, MG, 2017.

MIRANDA, Nívia Maria Ladeira. Discutindo sobre a evasão em uma Licenciatura em Matemática a distância. Dissertação de Mestrado. Universidade Federal de Viçosa, 2016.

QUARANTA, André Marsiglia. Formação de Professores de Educação Física na modalidade de Educação a Distância: experiências docentes no estágio supervisionado. Dissertação (Mestrado), 2011. Universidade Federal de Santa Catarina, UFSC, Brasil.

REIS, Sandra Regina dos. Estágio supervisionado no curso de pedagogia a distância: aproximações e diferenças do ensino presencial. 2015. Tese (doutorado) - Universidade Estadual Paulista, Faculdade de Ciências e Tecnologia. Presidente Prudente, 2015.

RELA, Eliana; ROCHA, Karla Marques da; SOARES, Marie Jane Soares de; Zini, Melissa. Supervisão e Construção da Avaliação em Situações de Estágio em Cursos de Licenciatura na Modalidade a Distância. Informática na Educação: teoria e prática Singularidades, coletivas e éticas. $1^{a}$ ed. UFRGS: Universidade Federal do Rio Grande do Sul, 2006, v. 9, p. 57-72. Disponível em: <http://www.lume.ufrgs.br/bitstream/handle/10183/23255/000629247.pdf?sequence=1. Acesso em: 18 de março de 2017.

ROCHA, Silviane da Silva. Ser professor em EaD: saberes e prática no estágio supervisionado do curso de pedagogia UAB/UECE. 2013. Dissertação (mestrado) - Universidade Estadual do Ceará, Centro de Educação, Curso de Mestrado Acadêmico em Educação, Fortaleza, 2013.

SANTOS, Adriana Alves Moreira dos. Um Retorno ao Presencial? O estágio supervisionado nos cursos de pedagogia na modalidade de educação a distância (EaD). 2014.123 pág. Dissertação (Mestrado) - Universidade Federal de Pernambuco, CE. Programa de Pós-graduação em Educação Matemática e Tecnológica, 2014. 
SANTOS, Silvana Claudia dos; VIEL, Silvia Regina. Formação de Professores de Matemática a Distância: um mosaico de pesquisa em construção. In: Marcelo de Carvalho Borba; Aparecida Chiari. (Org.). Tecnologias Digitais e Educação Matemática. 1ed.São Paulo: Editora Livraria da Física, 2013, v. 1, p. 251-272.

SCHWARTZ, Yves. A experiência é formadora. Tradução Daisy Moreira Cunha. Revista Educação e Realidade, v. 35, n. 1, p. 35-48, 2010.

SKOVSMOSE, Ole. Educação matemática crítica: a questão da democracia. Campinas, SP: Papirus, 2006.

UFV, Universidade Federal de Viçosa, Regime didático 2016 da graduação da UFV. Anexo da resolução 06/2015 - CEPE.

XAVIER, Jean Paulo Bernardo. 0 estágio supervisionado no curso de Licenciatura em Língua Inglesa em uma instituição de ensino superior na cidade de Paranaguá. In: IX Congresso Nacional de Educação - EDUCERE e III Encontro Sul Brasileiro de Psicopedagogia, 2009, Curitiba-PR/Brasil. Anais do Congresso Nacional de Educação. Curitiba: CHAMPAGNAT, 2009. v. 01.

ZANTEN, Agnès van. Pesquisa qualitativa em educação: pertinência, validez e generalização.

PERSPECTIVA, Florianópolis, v. 22, n. 01, p. 25-45, jan/ jun. 2004. Disponível em: $<$ <ttp://ced.ufsc.br/nucleos/nup/perspectiva.html>. Acesso em: 31 de março de 2017. 